\title{
Tumor-associated macrophage/microglia infiltration in human gliomas is correlated with MCP-3, but not MCP-1
}

\author{
MAKOTO OKADA ${ }^{1,2}$, MASANAO SAIO ${ }^{2}$, YUSUKE KITO ${ }^{2}$, NAOYUKI OHE ${ }^{1}$, HIROHITO YANO ${ }^{1}$, \\ SHINICHI YOSHIMURA ${ }^{1}$, TORU IWAMA ${ }^{1}$ and TSUYOSHI TAKAMI ${ }^{2}$ \\ Departments of ${ }^{1}$ Neurosurgery and ${ }^{2}$ Immunopathology, Gifu University Graduate \\ School of Medicine, 1-1 Yanagido, Gifu-city, Gifu 501-1194, Japan
}

Received January 20, 2009; Accepted February 25, 2009

DOI: 10.3892/ijo_00000292

\begin{abstract}
The monocyte chemotactic protein 3 (MCP-3) belongs to the MCP subgroup of the $\mathrm{CC}$ chemokines and promotes chemotaxis of immune cells. MCP-1 is believed to play an important role in monocyte infiltration into tumor tissues; however, the relationship between tumor-infiltrating macrophage/microglia (TIM/M) and the expression of chemokines has not been investigated in detail in human glioma samples; therefore, we first examined the expression of several chemokines and chemokine receptors in human tumor cell lines, which included glioma lines, using real-time PCR. We found that several glioma lines expressed MCP-3 predominantly, and not MCP-1. In order to assess the significance of MCP-3 expression in human glioma tissues, we then examined the number of $\mathrm{CD} 68^{+} \mathrm{TIM} / \mathrm{M}$, the percentage of TIM/M in the total cell population, and the expression of MCP-1 and MCP-3 in glioma tissues. There was a correlation between the percentage of TIM/M and MCP-3 expression levels; however, there was no correlation between the percentage of TIM/M and MCP-1 expression. There was no correlation between the number of TIM/M and prognosis of patients. These data indicate that tumor cell-derived MCP-3, but not MCP-1, facilitates the infiltration of macrophage/ microglia into tumor tissues. This is the first study that clearly compared the significance of MCP-3 with that of MCP-1 in the tumor infiltration rates of TIM/M.
\end{abstract}

\section{Introduction}

Chemokines promote immune cell chemotaxis. Over 18 chemokines have been identified to date. Recently, a growing number of reports addressed the effect of chemokines on tumor environment and tried to assess whether chemokines promote or suppress tumor progression. Several CC chemo-

Correspondence to: Dr Masanao Saio, Department of Immunopathology, Gifu University Graduate School of Medicine, 1-1 Yanagido, Gifu-city, Gifu 501-1194, Japan

E-mail: saio@gifu-u.ac.jp

Key words: glioma, monocyte chemotactic protein-1, monocyte chemotactic protein-3 kine gene transfer experiments have been performed, but a consensus has not yet been reached because of the multiple functions of chemokines. For example, monocyte chemotactic protein (MCP)-1, one of the best studied CC chemokines, has multiple functions and two-faced properties (1-7). However, in the case of tumor-infiltrating macrophages (TIM), the abundant infiltration of TIM into tumor tissues is achieved via the action of MCP-1 (8-11), and TIM infiltration correlates with a worse disease prognosis in many cases (12). In human gliomas, MCP-1 expression in the tumor tissue correlates with the recruitment of TIM/microglia (TIM/M) and has a poor disease prognosis (13-16). MCP-3 also belongs to the MCP subgroup of CC chemokines, which are structurally closely related but differ with respect to receptor usage; MCP-3 binds to the CCR1, CCR2, and CCR3 receptors, while MCP-1 binds exclusively to CCR2 (17). MCP-3 and MCP-1 activate monocytes, $\mathrm{T}$ cells, eosinophils, and natural killer (NK) cells. In addition, MCP-3 activates dendritic cells (18). Hence, the biological activities of MCP-1 and MCP-3 are thought to be distinct.

In comparison to MCP-1, it is unclear whether MCP-3 promotes tumor progression or not. However, there is evidence that MCP-3 might be a tumor suppressor. For instance, the transfection of MCP-3 into a rodent melanoma induced a type $1 \mathrm{~T}$ cell-dependent response, which resulted in the elimination of the melanoma (19).

An effect (or lack thereof) of MCP-3 expression on the recruitment of TIM/M into human gliomas has not yet been reported. Therefore, in the present study, we focused on investigating the relationship between the expression of MCP-1 and MCP-3 chemokines and TIM/M infiltration into human gliomas. To this effect, we determined which chemokines and chemokine receptors were expressed in several human tumor cell lines, which led to the confirmation of the expression of MCP-1 and MCP-3 in glioma cell lines. We then analyzed the relationship between these chemokines and infiltration of TIM/M in surgically obtained human glioma paraffin-embedded specimens using immunohistochemistry.

\section{Materials and methods}

Human glioma cell lines and human malignant tumor cell lines. The following cell lines were originally provided by 
Table I. Primer pairs for real-time PCR analysis.

Target gene

(Gene Bank accession no.)
Forward primer sequence: $\mathrm{F}\left(5^{\prime} \rightarrow 3^{\prime}\right)$

Lower primer sequence: $\mathrm{R}\left(5^{\prime} \rightarrow 3^{\prime}\right)$

\section{CCL2}

(NM 002982)

CCL3

(NM 002983)

CCL4

(NM 002984)

CCL5

(NM 002985)

CCL7

(NM 006273)

CCL8

(NM 005623)

CXCL12 transcript variant 1

(NM 199168)

CXCL12 transcript variant 3

(NM 001033886)

CCR2 transcript variant A

(NM 000647)

CCR2 transcript variant B

(NM 000648)

CCR3

(NM 001837)

CCR5

(NM 000579)

CXCR4

(NM 001008540)
F: GCTCATAGCAGCCACCTTCATTC

R: GGACACTTGCTGCTGGTGATTC

F: CCTGCTCAGAATCATGCAGGTC

R: AGCACTGGCTGCTCGTCTCA

F: CTAGTAGCTGCCTTCTGCTCTCCAG

R: AATCTACCACAAAGTTGCGAGGAAG

F: ACCAGTGGCAAGTGCTCCAAC

R: CTCCCAAGCTAGGACAAGAGCAAG

F: TCCCTAAGCAGAGGCTGGAGA

R: CTTCATAAAGTCCTGGACCCACTTC

F: TGCTCATGGCAGCCACTTTC

R: CACGTTAAAGCAGCAGGTGATTG

F: AAATCTGAGAGCTCGCTTTGAGTGA

R: GTTTGTTAGTGCCTCCATGGCATAC

F: GAGCCAACGTCAAGCATCTCAA

R: TTTAGCTTCGGGTCAATGCACA

F: AAGCACCAGTCAACTGGACCAAG

R: GGCAATCCTACAGCCAAGAGCTA

F: ATGCCTCATTACCTTGTGCTAATCC

R: CCCATTCATCTGTGCCTGTCA

F: TACAAGGCCATCCGGCTCA

R: TTGCTCCGCTCACAGTCATTTC

F: CCACAGGCAGCATTTAGCACA

R: ACTGGGCAGGCAGCATCTTAG

F: GCCAACGTCAGTGAGGCAGA

R: GCCAACCATGATGTGCTGAAAC the American Type Culture Collection: human glioma cell lines (U373, U87, T98G, A172, and SNB19), human squamous carcinoma cell line (HSC-3), human hepatocellular carcinoma cell line (HuH-7), human Burkitt's lymphoma cell line (RAJI), human cervical cancer cell line (HeLa), and human diffuse histiocytic lymphoma cell line (U937), lung adenocarcinoma cell line A549. These tumor cells were cultured in RPMI-1640 medium supplemented with L-glutamine (Sigma Aldrich, St. Louis, MO), $10 \%$ fetal calf serum (FCS), and penicillinstreptomycin (Sigma Aldrich). The cells were maintained at $37^{\circ} \mathrm{C}$ in a humidified $5 \% \mathrm{CO}_{2}$ atmosphere.

Polymerase chain reaction (PCR). Total RNA was prepared using the TRIzol reagent (Invitrogen, Carlsbad, CA) and $600 \mathrm{ng}$ were subjected to reverse transcription (RT) using Superscript III reverse transcriptase. Five microliters of 20x diluted cDNA samples, $1 \mu 1$ each of forward and reverse primers $(10 \mu \mathrm{M}), 3 \mu \mathrm{l}$ of PCR-grade water (Roche) and $10 \mu \mathrm{l}$ of $2 x$ concentrated SYBR green and Taq enzyme premixed reaction mixture $\left(\mathrm{SYBR}^{\circledR}\right.$ Premix Ex Taq ${ }^{\mathrm{TM}}$, Takara) were used for real-time PCR analysis. The sequences of the primer pairs used in this analysis are indicated in Table I. The reaction conditions consisted of one $5 \mathrm{~min}$ incubation at $95^{\circ} \mathrm{C}$ followed by 45 cycles of $95^{\circ} \mathrm{C}$ for $10 \mathrm{sec}, 60^{\circ} \mathrm{C}$ for $10 \mathrm{sec}$, and $72^{\circ} \mathrm{C}$ for $10 \mathrm{sec}$, which were assessed by melting curve analysis. The reactions and analyses were performed on a LightCycler (Roche).

Human glioma samples. Surgically removed human glioma samples were fixed in $4 \%$ paraformaldehyde in phosphatebuffered saline (PBS) and were then embedded in paraffin. Sections $(4 \mu \mathrm{m})$ were prepared and stained with hematoxylin and eosin (H\&E) for pathological diagnosis. Paraffin blocks were used in accordance with the guidelines of the Ethics 

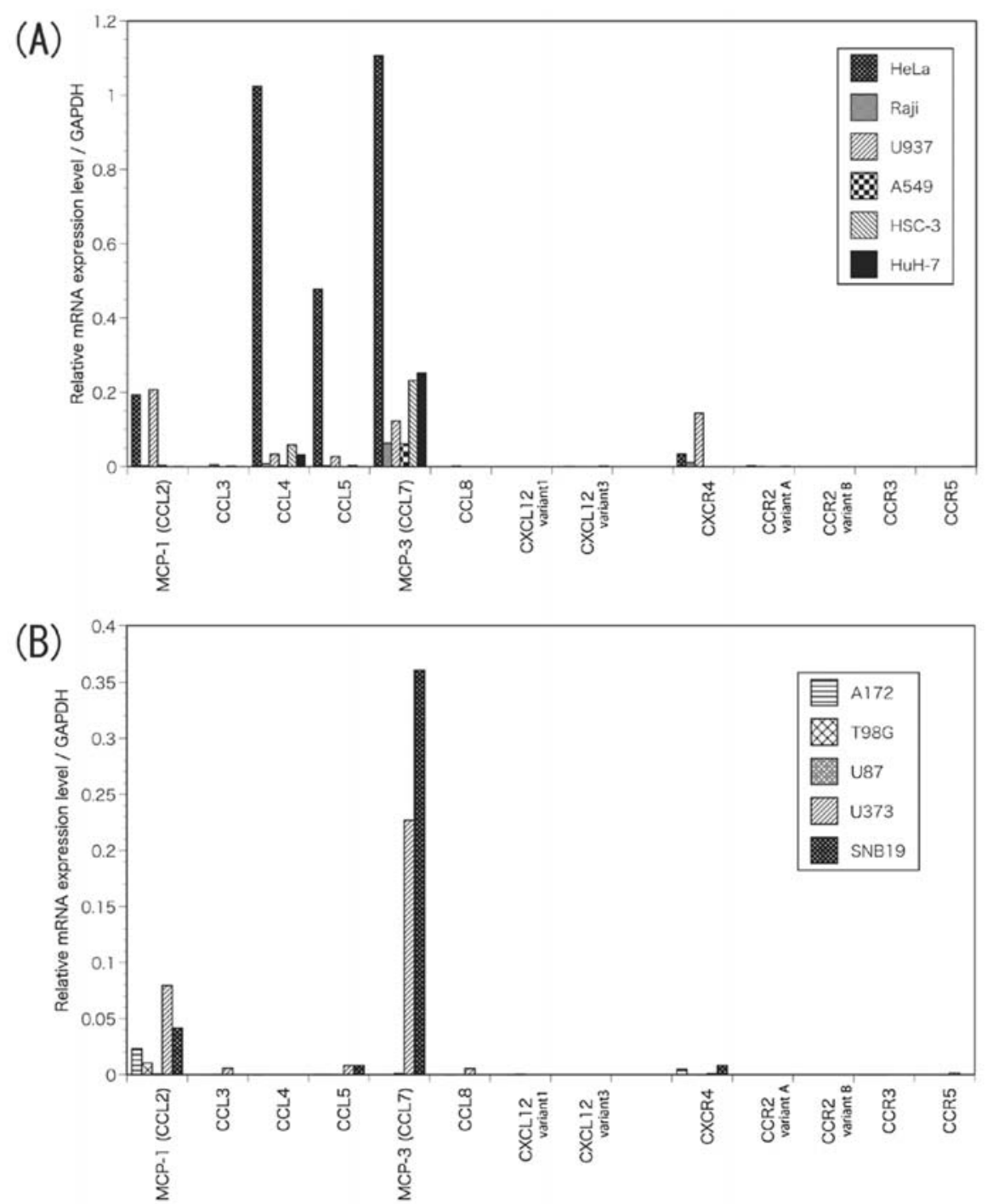

Figure 1. Relative expression levels of chemokines and chemokine receptor genes in the in vitro human malignant cell lines. Quantitative RT-PCR was carried out in non-glioma cell lines (A) or glioma cell lines (B). The relative amount of the mRNA of each molecule was normalized to the levels of GAPDH mRNA.

Committee of the Gifu University School of Medicine. Thirty-six cases of glioma were analyzed as described below.

Immunohistochemical analysis. Sections $(4 \mu \mathrm{m})$ were prepared and specimens were deparaffinated and rehydrated. Each specimen was autoclaved in $10 \mathrm{mM}$ citrate buffer $\mathrm{pH} 7.0$ at $121^{\circ} \mathrm{C}$ for $10 \mathrm{~min}$, followed by washing with PBS. The specimens were stained with $10 \mu \mathrm{g} / \mathrm{ml}$ of mouse anti-human MCP-1 (clone 23002, mouse IgG2b, R\&D System Inc.), mouse anti-human MCP-3 (clone polyclone, LifeSpan Biosciences), and mouse anti-human CD68 (clone KP-1, mouse $\mathrm{IgG} 1 \kappa$, Dako) for $1 \mathrm{~h}$ at room temperature (RT) in a humidified chamber. After washing $3 \times 10$ min with PBS, the specimens were stained with Histofine Simple Stain MAX-PO(M) ${ }^{\circledR}$ horseradish peroxidase-conjugated goat anti-mouse IgG (Nichirei Biosciences, Tokyo, Japan) for $1 \mathrm{~h}$ at RT. After washing 3x10 min with PBS, immunoreactions were visualized by incubation for $10 \mathrm{~min}$ in a solution containing $0.035 \%$ $\mathrm{H}_{2} \mathrm{O}_{2}$ and $0.03 \%$ 3,3'-diaminobenzidine (Wako, Tokyo, Japan) in $50 \mathrm{mM}$ Tris- $\mathrm{HCl}$ (pH 7.6). Sections were fixed in $4 \%$ paraformaldehyde for $10 \mathrm{~min}$ and were then counterstained with $H \& E$ and submitted for observation.
Analysis of stained sections. We observed each specimen at magnification $\mathrm{x} 400$ using a $10-\mathrm{mm}$ square (1 mm divisions) micrometer (Olympus, Tokyo, Japan); thus, each observation represented an actual area of $0.25 \times 0.25 \mathrm{~mm}$. We counted at least 400 hematoxylin-positive cells as the total number of the cells, and the number of $\mathrm{CD} 68^{+}$cells was counted simultaneously in the same field.

Statistical analysis. We used the Mann-Whitney U test for single parameter comparisons. We used regression analysis to assess the correlation between two parameters. Probability values $<0.05$ were considered significant.

\section{Results}

MCP-1 and MCP-3 were highly expressed in tumor cell lines when compared with other chemokines. We examined the expression levels of chemokines and chemokine receptors in a variety of human tumor cell lines (Fig. 1). The expression levels of CCL3 and CCL4 were very low in the lines examined, with the exception of HeLa cells. In addition, MCP-1 expression was observed in 2 out of 5 non-glioma tumors, and in 
Table II. Clinical data for the 36 glioma cases.

Age (year, mean \pm SD)

$45.8 \pm 20.9$

Sex

Female

Male

\begin{tabular}{clr} 
WHO grade & \\
II & Diffuse astrocytoma & 9 \\
III & Anaplastic astrocytoma & 8 \\
IV & Glioblastoma & 19 \\
\hline
\end{tabular}

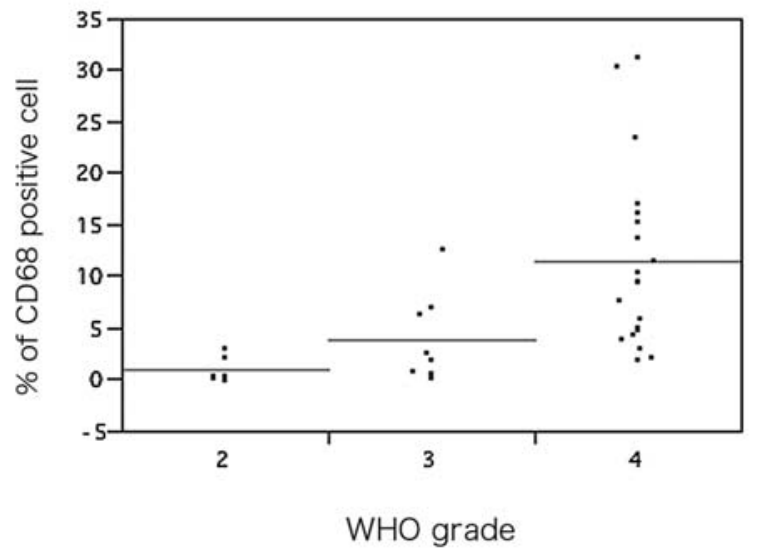

Figure 2. Relationship between the percentage of $\mathrm{CD} 68^{+}$cells and WHO grade of gliomas. Single-scatter plots of the percentage of $\mathrm{CD}^{2} 8^{+}$cells in total cells in each tumor tissue sample according to WHO grade of glioma are shown. The Mann-Whitney U test was used for statistical analysis $(\mathrm{P}<0.001)$.

4 out of 5 glioma tumors. Non-glioma tumor cell lines all expressed MCP-3 and 2 out of 5 glioma tumors expressed this chemokine; however, the expression levels of MCP-3 in glioma cases were much higher than those observed for MCP-1 in all glioma cases. The MCP-1 and MCP-3 common receptors were not expressed in any of the tumors analyzed, with the exception of the low expression of CXCR4 on A172 and SNB19. These data indicate that, similarly to that observed for MCP-1, MCP-3 could be a candidate molecule secreted by tumor cells and involved in the chemotaxis of monocytes to tumor sites. The high expression of MCP-3 suggests that this molecule may be a predominant factor affecting the infiltration of monocytes into tumor sites.

Percentage of TIM/M in human glioma tissue samples correlated with WHO grade of the tumors. Because the density of TIM is generally correlated with a worse disease prognosis (12), we examined the number of TIM/M in surgically removed human glioma tumor tissue samples using CD68 staining, as CD68 is a marker of macrophages (20) and microglia (21). The clinicopathological data of all cases are summarized in Table II. As shown in Fig. 2, the percentage of TIM/M versus the total number of cells in the

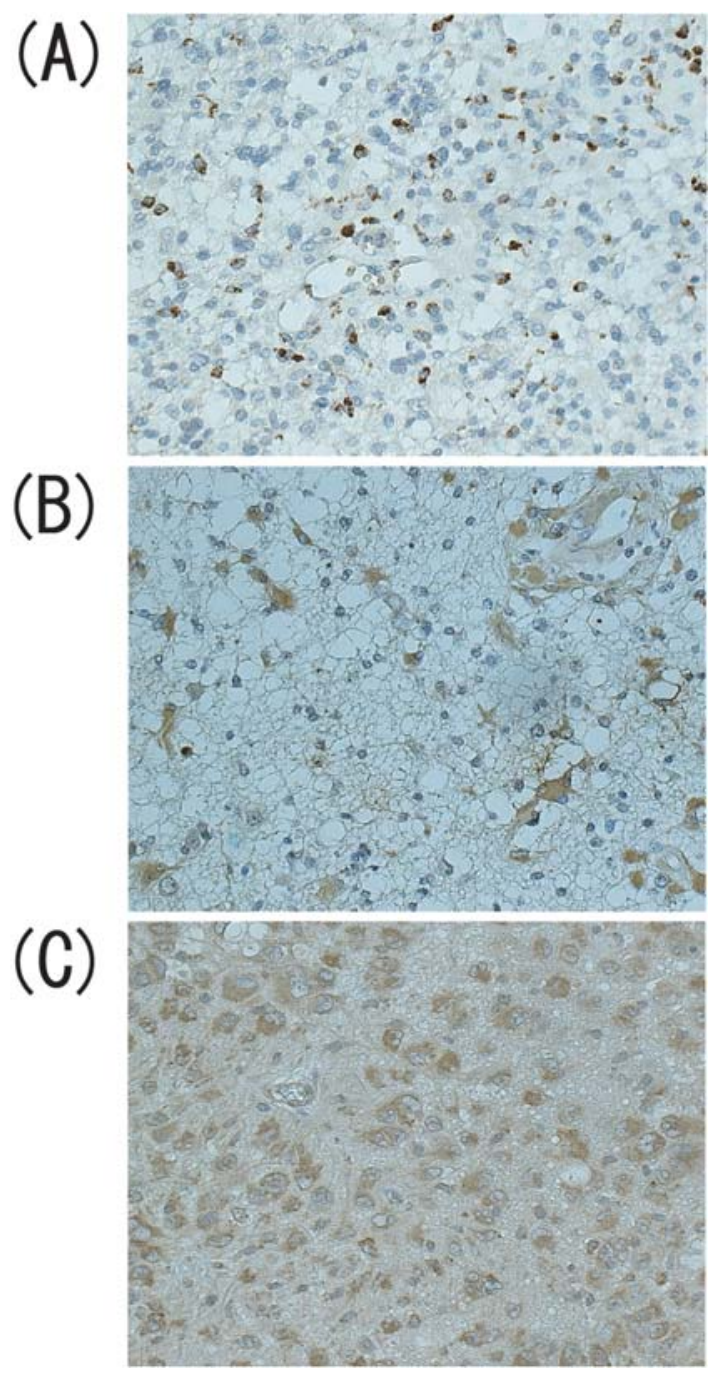

Figure 3. Representative staining of $\mathrm{CD}^{+} 8^{+}$, $\mathrm{MCP}-1$, and $\mathrm{MCP}-3$ on glioma tissue sections. (A) Infiltration of macrophages/microglia in glioma. The tissue section was stained with an anti-CD68 antibody (no. 7, x400). (B) MCP-1 expression in a glioma tissue sample. The tissue section was stained with an anti-MCP-1 antibody (no. 27, x400). (C) MCP-3 expression in a glioma tissue sample. The tissue section was stained with an anti-MCP-3 antibody (no. 7, x400)

tumor tissue seemed to increase with increasing WHO grade of the glioma.

The infiltration of TIM/M in human gliomas correlated with MCP-3 expression patterns, but not with those of MCP-1. Next, we examined the expression of MCP-1 and MCP-3 and calculated the number of TIM/M in tumor tissue samples. The representative staining patterns of MCP-1, MCP-3, and CD68 are shown in Fig. 3 (case nos. 7 and 32). MCP-1 and MCP-3 staining was preferentially detected in cells exhibiting nuclear atypia or in large cells (rather than in mononuclear cells). This indicated that MCP-1 and MCP-3 were predominantly expressed in tumor cells; therefore, we classified tumors into MCP-1- or MCP-3-positive and -negative status: the immunohistochemical analysis results for each specimen are summarized in Table III. As shown in Fig. 4A, there were no significant differences in CD68 staining between MCP-1negative and -positive cases $(\mathrm{P}=0.1404)$. In contrast, there 
Table III. Summary of immunohistochemical staining of the 36 specimens.

\begin{tabular}{|c|c|c|c|c|c|c|}
\hline No. & Age & Sex & WHO grade & CD68 \% & MCP-1 & $\mathrm{MCP}-3$ \\
\hline 1 & 53 & $\mathrm{M}$ & 4 & 5.79 & - & - \\
\hline 2 & 65 & $\mathrm{M}$ & 4 & 7.67 & + & + \\
\hline 3 & 61 & $\mathrm{~F}$ & 3 & 7.02 & + & + \\
\hline 4 & 40 & $\mathrm{M}$ & 4 & 4.79 & - & + \\
\hline 5 & 11 & $\mathrm{~F}$ & 3 & 6.38 & + & + \\
\hline 6 & 38 & $\mathrm{M}$ & 3 & 0.67 & - & - \\
\hline 7 & 57 & $\mathrm{M}$ & 4 & 31.29 & - & + \\
\hline 8 & 56 & $\mathrm{M}$ & 4 & 10.39 & - & + \\
\hline 9 & 68 & $\mathrm{~F}$ & 4 & 11.42 & + & + \\
\hline 10 & 59 & $\mathrm{~F}$ & 4 & 2.11 & - & - \\
\hline 11 & 53 & M & 4 & 23.43 & - & + \\
\hline 12 & 56 & M & 4 & 5.04 & + & + \\
\hline 13 & 68 & $\mathrm{~F}$ & 4 & 4.26 & - & + \\
\hline 14 & 73 & $\mathrm{~F}$ & 3 & 12.52 & + & + \\
\hline 15 & 13 & $\mathrm{~F}$ & 4 & 3.78 & - & + \\
\hline 16 & 52 & $\mathrm{~F}$ & 4 & 16.89 & - & + \\
\hline 17 & 64 & M & 4 & 15.23 & - & + \\
\hline 18 & 60 & $\mathrm{M}$ & 4 & 13.68 & - & + \\
\hline 19 & 60 & $\mathrm{M}$ & 4 & 30.36 & + & + \\
\hline 20 & 59 & $\mathrm{M}$ & 4 & 3.02 & - & - \\
\hline 21 & 65 & $\mathrm{M}$ & 4 & 2.00 & + & - \\
\hline 22 & 33 & $\mathrm{M}$ & 4 & 16.15 & + & + \\
\hline 23 & 42 & $\mathrm{~F}$ & 4 & 9.50 & + & + \\
\hline 24 & 19 & $\mathrm{M}$ & 3 & 0.49 & - & - \\
\hline 25 & 0.5 & $\mathrm{~F}$ & 3 & 0.21 & + & - \\
\hline 26 & 69 & $\mathrm{M}$ & 3 & 2.48 & + & - \\
\hline 27 & 65 & $\mathrm{M}$ & 3 & 1.88 & + & - \\
\hline 28 & 25 & $\mathrm{M}$ & 2 & 0 & + & - \\
\hline 29 & 46 & $\mathrm{M}$ & 2 & 2.05 & + & - \\
\hline 30 & 2 & $\mathrm{~F}$ & 2 & 3.09 & + & - \\
\hline 31 & 7 & $\mathrm{~F}$ & 2 & 0.30 & + & - \\
\hline 32 & 61 & $\mathrm{M}$ & 2 & 0 & + & - \\
\hline 33 & 54 & $\mathrm{~F}$ & 2 & 0.41 & + & - \\
\hline 34 & 36 & $\mathrm{M}$ & 2 & 0.20 & + & - \\
\hline 35 & 32 & $\mathrm{~F}$ & 2 & 2.93 & + & - \\
\hline 36 & 26 & $\mathrm{M}$ & 2 & 0 & + & - \\
\hline
\end{tabular}

F, female; M, male.

was a significant difference in CD68 staining between MCP-3negative and-positive cases $(\mathrm{P}<0.001)$ (Fig. 4B). Furthermore, the classification of the tumors into four groups based on the staining pattern of MCP-1 and MCP-3 revealed that MCP-3-positive cases had a significantly higher level of infiltration of macrophages/microglia. These data clearly indicate that, of the two chemokines studied here, MCP-3 is the predominant factor for macrophage/microglia infiltration into tumor tissues.
(A)

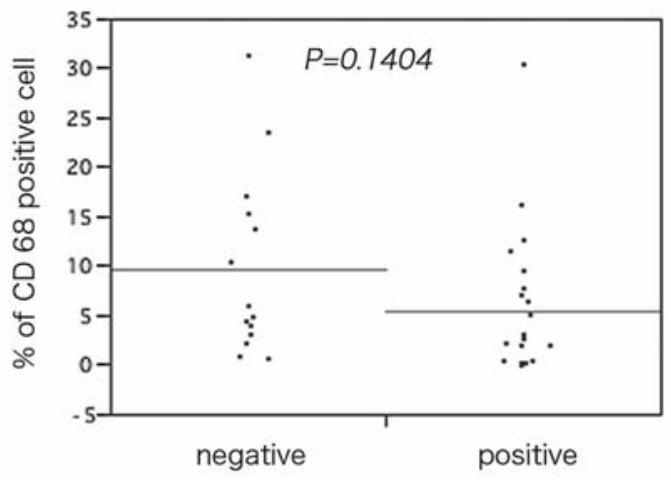

MCP-1

(B)

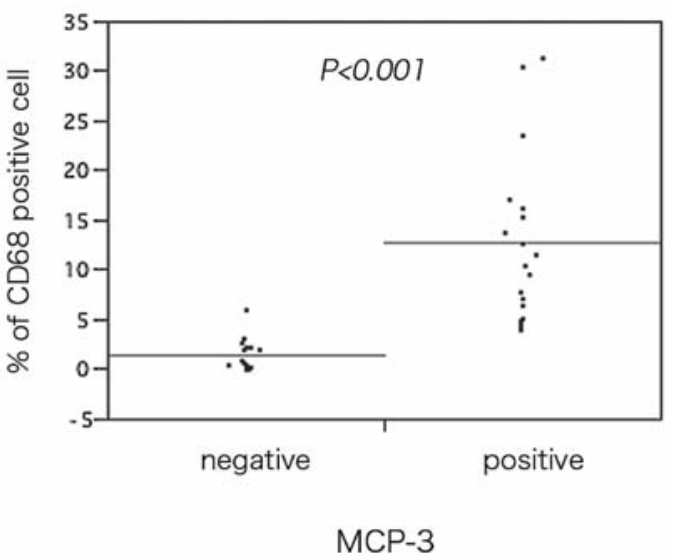

Figure 4. Relationship between the percentage of $\mathrm{CD} 68^{+}$cells and the expression of MCP-1 and MCP-3. (A) Single-scatter plots of $\mathrm{CD}^{2} 8^{+}$cells in MCP-1-negative and -positive tissue samples. (B) Single-scatter plots of CD68 ${ }^{+}$cells in MCP-3-negative and -positive tissue samples. The Student's $\mathrm{t}$-test was performed for each statistical analysis.

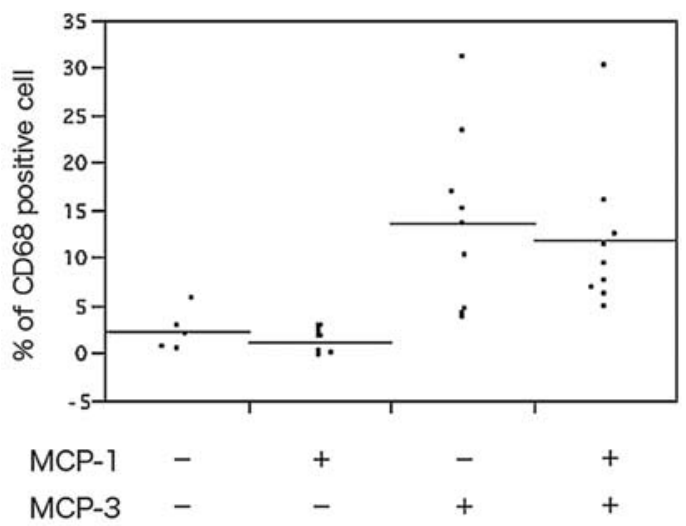

Figure 5. Relationship between the percentage of $\mathrm{CD} 68^{+}$cells and the staining patterns of MCP-1 and MCP-3. The means of the percentage of $\mathrm{CD} 68^{+}$cells are represented by horizontal bars.

\section{Discussion}

In the present study, we focused on the involvement of MCP-3 expression in the infiltration of macrophages/microglia into tumor tissues. The expression level of the MCP-3 mRNA in glioma cell lines was higher than that of MCP-1 (Fig. 1B). Moreover, we showed that the percentage of TIM/M was 
significantly higher in MCP-3-positive human glioma specimens, regardless of the expression status of MCP-1 (Figs. 4 and 5). As regards the mechanism underlying the exclusive correlation between MCP-3 expression (but not MCP-1 expression) and macrophage/microglia infiltration, two possibilities can be envisaged on the basis of previously published work. First, the potential involvement of matrix metalloproteinase (MMP) can be considered because MMP-1, 2, 9 (22-24) and MMP-3 (25) expression has been reported in human glioma tissue samples or glioma cell lines. MMP-1 and MMP-3 cleave both MCP-1 and MCP-3, which results in inactivation of both chemokines, and MMP-2, 13, and 14 cleave MCP-3 but not MCP-1 $(26,27)$. Thus, if MMP-1 or 3 were activated to cleave both chemokines, this would result in the inactivation of both chemokines. Furthermore, if MMP-2, 13, or 14 were activated to cleave MCP-3, the truncated MCP-3 would also interfere with MCP-1 function as truncated MCP-3 binds to all its receptors including the MCP-1 receptor CCR2. However, our results clearly showed a specific correlation between MCP-3 expression (but not MCP-1 expression) and the infiltration of TIM/M. Therefore, MMPs would not appear to be strongly involved in the regulation of MCP-1 and MCP-3 cleavage in our study. Second, the differences in receptor usage between MCP-1 and MCP-3 suggest another possibility. As mentioned in the Introduction, MCP-1 binds to CCR2 exclusively, whereas MCP-3 binds to CCR1, CCR2, and CCR3 (17). Human CD14+ monocytes express both CCR1 and CCR2 (28). This implies that MCP-3, but not MCP-1, can activate both receptors in monocytes. In addition, an MCP-1 knockout mouse does not exhibit diminished infiltration of macrophages (29). These reports suggest that $\mathrm{MCP}-3$ is more important in monocyte recruitment into peripheral tissues than $\mathrm{MCP}-1$.

As shown in Fig. 2, immunohistochemical staining for CD68 in human glioma specimens revealed that the percentage of TIM/M significantly increased with the increasing WHO grade of glioma (Fig. 2); however, we did not find a correlation between the percentage of TIM/M and disease prognosis (data not shown), in agreement with what was reported by Yao et al (30). Regarding the absence of a correlation between CD68+TIM/M infiltration and patient prognosis, we should consider the status of TIM/M activation as several different classifications have been proposed for monocyte/macrophage activation $(31,32)$, and tumor-infiltrating macrophages are preferentially activated toward alternatively activated phenotypes (33). The scavenger receptor CD136 and the mannose receptor CD204 are markers of the alternatively activated phenotype of TIM/M. Interestingly, a recent study mentioned the effect of the expression of CD136 and CD204 in TIM/M on the prognosis of glioma patients (34). Although we showed tumor cell-derived MCP-3 played a predominant role in the recruitment of macrophage/microglia into tumor tissues, the infiltration was not sufficient for the maintencance of the immunosuppressive property of the TIM/M; rather activation/maturation towards alternatively activated phenotype was the important factor. As described above, MCP-3 acts not only on monocytes but also on several types of leukocytes (18); therefore, neither the neutralization nor the blocking of MCP-3 can be used to prevent monocyte/macrophage infiltration. Instead, the prevention of macrophage activation toward an alternatively activated phenotype should be considerd to be the target of choice for immunotherapy of cancer patients.

In conclusion, we showed the significance of MCP-3 for infiltration of TIM/M into human glioma tissue samples. This is the first report on human glioma samples to show the significance of glioma cell-derived MCP-3 for the recruitment of TIM/M.

\section{References}

1. Hirose K, Hakozaki M, Nyunoya Y, et al: Chemokine gene transfection into tumour cells reduced tumorigenicity in nude mice in association with neutrophilic infiltration. Br J Cancer 72: 708-714, 1995.

2. Rollins BJ and Sunday ME: Suppression of tumor formation in vivo by expression of the JE gene in malignant cells. Mol Cell Biol 11: 3125-3131, 1991.

3. Bottazzi B, Walter S, Govoni D, et al: Monocyte chemotactic cytokine gene transfer modulates macrophage infiltration, growth, and susceptibility to IL-2 therapy of a murine melanoma. J Immunol 148: 1280-1285, 1992.

4. Walter S, Bottazzi B, Govoni D, et al: Macrophage infiltration and growth of sarcoma clones expressing different amounts of monocyte chemotactic protein/JE. Int J Cancer 49: 431-435, 1991.

5. Mule JJ, Custer M, Averbook B, et al: RANTES secretion by gene-modified tumor cells results in loss of tumorigenicity in vivo: role of immune cell subpopulations. Hum Gene Ther 7: 1545-1553, 1996.

6. Dilloo D, Bacon K, Holden W, et al: Combined chemokine and cytokine gene transfer enhances antitumor immunity. Nat Med 2: 1090-1095, 1996.

7. Mantovani A, Bottazzi B, Sozzani S, et al: Cytokine regulation of tumour-associated macrophages. Res Immunol 144: 280-294, 1993.

8. Bottazzi B, Polentarutti N, Balsari A, et al: Chemotactic activity for mononuclear phagocytes of culture supernatants from murine and human tumor cells: evidence for a role in the regulation of the macrophage content of neoplastic tissues. Int J Cancer 31: $55-63,1983$.

9. Graves DT, Jiang YL, Williamson MJ, et al: Identification of monocyte chemotactic activity produced by malignant cells. Science 245: 1490-1493, 1989.

10. Mantovani A, Bottazzi B, Colotta F, et al: The origin and function of tumor-associated macrophages. Immunol Today 13: 265-270, 1992.

11. Van Damme J, Decock B, Lenaerts JP, et al: Identification by sequence analysis of chemotactic factors for monocytes produced by normal and transformed cells stimulated with virus, doublestranded RNA or cytokine. Eur J Immunol 19: 2367-2373, 1989.

12. Lewis CE and Pollard JW: Distinct role of macrophages in different tumor microenvironments. Cancer Res 66: 605-612, 2006.

13. Platten M, Kretz A, Naumann U, et al: Monocyte chemoattractant protein-1 increases microglial infiltration and aggressiveness of gliomas. Ann Neurol 54: 388-392, 2003.

14. Takeshima H, Kuratsu J, Takeya M, et al: Expression and localization of messenger RNA and protein for monocyte chemoattractant protein-1 in human malignant glioma. J Neurosurg 80 : 1056-1062, 1994.

15. Leung SY, Wong MP, Chung LP, et al: Monocyte chemoattractant protein-1 expression and macrophage infiltration in gliomas. Acta Neuropathol 93: 518-527, 1997.

16. Desbaillets I, Tada M, De Tribolet N, et al: Human astrocytomas and glioblastomas express monocyte chemoattractant protein-1 (MCP-1) in vivo and in vitro. Int J Cancer 58: 240-247, 1994.

17. Rot A and von Andrian UH: Chemokines in innate and adaptive host defense: basic chemokinese grammar for immune cells. Annu Rev Immunol 22: 891-928, 2004.

18. Menten P, Wuyts A and van Damme J: Monocyte chemotactic protein-3. Eur Cytokine Netw 12: 554-560, 2001.

19. Fioretti F, Fradelizi D, Stoppacciaro A, et al: Reduced tumorigenicity and augmented leukocyte infiltration after monocyte chemotactic protein-3 (MCP-3) gene transfer: perivascular accumulation of dendritic cells in peritumoral tissue and neutrophil recruitment within the tumor. J Immunol 161: 342-346, 1998. 
20. Andjelkovic AV, Nikolic B, Pachter JS, et al: Macrophages microglial cells in human central nervous system during development: an immunohistochemical study. Brain Res 814: $13-25,1998$

21. Hulette CM, Downey BT and Burger PC: Macrophage markers in diagnostic neuropathology. Am J Surg Pathol 16: 493-499, 1992.

22. Rao JS, Steck PA, Mohanam S, et al: Elevated levels of M(r) 92,000 type IV collagenase in human brain tumors. Cancer Res 53: 2208-2211, 1993.

23. Forsyth PA, Wong H, Laing TD, et al: Gelatinase-A (MMP-2), gelatinase-B (MMP-9) and membrane type matrix metalloproteinase-1 (MT1-MMP) are involved in different aspects of the pathophysiology of malignant gliomas. Br J Cancer 79: 1828-1835, 1999.

24. McCawley LJ and Matrisian LM: Matrix metalloproteinases: they're not just for matrix anymore! Curr Opin Cell Biol 13: 534-540, 2001.

25. Mercapide J, Lopez De Cicco R, Castresana JS, et al: Stromelysin1/matrix metalloproteinase-3 (MMP-3) expression accounts for invasive properties of human astrocytoma cell lines. Int J Cancer 106: 676-682, 2003.

26. McQuibban GA, Gong JH, Wong JP, et al: Matrix metalloproteinase processing of monocyte chemoattractant proteins generates CC chemokine receptor antagonists with antiinflammatory properties in vivo. Blood 100: 1160-1167, 2002.
27. McQuibban GA, Gong JH, Tam EM, et al: Inflammation dampened by gelatinase A cleavage of monocyte chemoattractant protein-3. Science 289: 1202-1206, 2000.

28. Serbina NV, Jia T, Hohl TM, et al: Monocyte-mediated defense against microbial pathogens. Annu Rev Immunol 26: 421-452, 2008.

29. Kirk EA, Sagawa ZK, McDonald TO, et al: Macrophage chemoattractant protein-1 deficiency fails to restrain macrophage infiltration into adipose tissue. Diabetes 57: 1254-1261, 2008.

30. Yao Y, Kubota T, Sato K, et al: Macrophage infiltrationassociated thymidine phosphorylase expression correlates with increased microvessel density and poor prognosis in astrocytic tumors. Clin Cancer Res 7: 4021-4026, 2001.

31. Gordon S and Taylor PR: Monocyte and macrophage heterogeneity. Nat Rev Immunol 5: 953-964, 2005.

32. Mantovani A, Sica A, Sozzani S, et al: The chemokine system in diverse forms of macrophage activation and polarization. Trends Immunol 25: 677-686, 2004.

33. Mantovani A, Allavena P and Sica A: Tumour-associated macrophages as a prototypic type II polarised phagocyte population: role in tumour progression. Eur J Cancer 40: 16601667,2004

34. Komohara Y, Ohnishi K, Kuratsu J, et al: Possible involvement of the M2 anti-inflammatory macrophage phenotype in growth of human gliomas. J Pathol 216: 15-24, 2008. 